\title{
SUPERLOW-FRICTION CARBON FILMS FOR USE IN FUEL SYSTEM COMPONENTS OPERATING IN LOW-SULFUR DIESEL FUELS*
}

\author{
A. Erdemir, J. Kavich, J. Woodford, L. Ajayi, and G. Fenske \\ Energy Technology Division \\ Argonne National Laboratory \\ Argonne, IL 60439
}

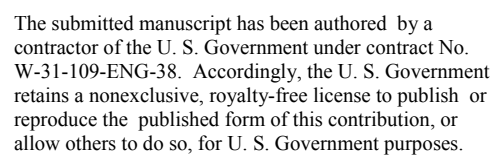

May 2001

Paper of presentation at 2001 SAE International Fuels and Lubricants Meeting September 23-27, 2001, San Antonio, TX

*Work supported by the U.S. Department of Energy, Office of Transportation Technologies, under Contract W-31-109-Eng-38. 


\title{
SUPERLOW-FRICTION CARBON FILMS FOR USE IN FUEL SYSTEM COMPONENTS OPERATING IN LOW-SULFUR DIESEL FUELS
}

\author{
A. Erdemir, J. Kavich, J. Woodford, L. Ajayi, and G. Fenske \\ Energy Technology Division \\ Argonne National Laboratory
}

Argonne, IL 60439

\begin{abstract}
In this paper, we will demonstrate the effectiveness and usefulness of a new class of superlowfriction carbon films in alleviating the wear and scuffing problems associated with the use of low sulfur diesel fuels in fuel delivery systems of advanced diesel engines. Specifically, using a wellestablished diesel fuel lubricity test machine, we will show that with the use of very thin (1micrometer-thick), superlubricious carbon films one can restore lubricity, virtually eliminate scuffing and potential wear failures that can occur in low-sulfur, super-clean, and zero sulfur (Fischer Tropsch) diesel fuels. Test results of our study raise the prospect for using such carbon coatings to solve problems associated with the use of low-sulfur diesel fuels and high injection pressures in future engines.
\end{abstract}

\section{INTRODUCTION}

Because of their high efficiency and reliability, diesel engines are the dominant power source for heavy-duty trucks, buses, and earth-moving machines worldwide. Diesel fuels used in these engines contain large amounts (i.e., 300 to $3000 \mathrm{ppm}$ ) of sulfur that mainly comes from the crude oil. At such high concentrations, sulfur helps provide lubricity to fuel pumps and injector systems [1-3], however, it also causes air-polluting emissions, particularly $\mathrm{SO}_{2}$ and soot particles. Furthermore, sulfur has a poisoning effect on the advanced emission-control or after-treatment devices that are essential for controlling NOx and other remaining pollutants in exhaust gases. Comprehensive tests have demonstrated that the elimination of sulfur from diesel fuels can significantly reduce the amount of soot particles and other gaseous emissions. Accordingly, EPA has proposed cutting the sulfur content of diesel fuel to $15 \mathrm{ppm}$ beginning June 1, 2006. Filtering out sulfur at the refinery can solve the problem, but doing so degrades the lubricity of the fuel and would quickly lead to catastrophic failures of fuel system components. In short, despite significant advances over the past 20 years, diesel engines continue to pose major challenges as well as opportunities for automotive engineers.

Currently, several approaches are being explored by various research groups around the world to circumvent the problems caused by sulfur in diesel fuels. One approach involves the replacement of sulfur in diesel fuel with other organic/inorganic additives that can restore the lubricity of diesel fuels while simultaneously reducing particulate emissions [4-8]. A second logical approach 
is to develop and implement new materials or protective coatings that can provide high scuff resistance to sliding or reciprocating surfaces of fuel pump components and injector parts. The scope of this paper falls in the areas of the second approach. Specifically, it involves the development and use of a hard and super-low-friction carbon coating that can potentially eliminate the friction and wear problems experienced currently in fuel injection systems running in low-sulfur diesel fuels or at high injection pressures (above $20 \mathrm{ksi}$ ) needed to minimize particulate emissions.

Extensive tests in our laboratory have confirmed that new carbon films developed in our laboratory can provide friction coefficients of 0.001-0.005 (this is the main reason for calling it near-frictionless carbon, or NFC) when measured in dry nitrogen $[9,10]$. When tested in moist air, the friction coefficient increases but is still considered very low, i.e., 0.02 to 0.06 . Furthermore, the new carbon film affords extremely low wear rates (i.e., $10^{-10}-5 \times 10^{-11} \mathrm{~mm}^{3} / \mathrm{N} . \mathrm{m}, 100$ to 1000 times lower than those of other commercial diamondlike carbon films) against steel and ceramic balls. These initial findings have raised the prospect that with further optimization (i.e., coating adhesion, thickness, and composition), these NFC coatings can be produced on the rubbing surfaces of fuel pumps and injector systems to solve the scuffing and severe wear problems experienced with the use of low-sulfur or ultra-clean diesel fuels (especially at high injection pressures). The NFC coating is chemically stable and highly inert, and hence should help increase the corrosion resistance of the fuel injector parts in low sulfur diesel as well as alcohol-containing fuels. A unique feature of the NFC film is that it can be deposited on virtually any substrate at room temperature and at growth rates comparable to those of the titanium nitride and titanium carbide films currently produced in large volumes and used for a number of engine applications.

\section{EXPERIMENTAL PROCEDURES}

\section{Deposition of Carbon Films}

Near-frictionless carbon (NFC) films used in this study were deposited on the surfaces of AISI 52100 disks using a plasma-enhanced chemical vapor deposition (PECVD) system. The films were about $1 \mu \mathrm{m}$ thick and were produced in pure methane and hydrogen rich methane plasmas at room temperature. The procedure for forming NFC films on steel substrates involved sputtercleaning of the substrates in an Ar plasma for $30 \mathrm{~min}$. The substrates were then coated with a 50$70 \mathrm{~nm}$ thick silicon bond layer by either physical vapor deposition from a silicon target or PECVD from silane $\left(\mathrm{SiH}_{4}\right)$ gas. Finally, carbon-bearing methane source gas was bled into the chamber and the deposition of carbon on the substrates was started; gas pressure ranged from 10 to 30 mtorr. Further details of the deposition process are provided in Refs. 9 and 10.

\section{Lubricity Tests}

Diesel fuel lubricity tests were conducted in a ball-on-three-disk (BOTD) machine available from Falex Co. and the test results were reported in appropriate charts. Figure 1 shows the schematic illustration of this test machine whose detailed description can be found in previous papers (see for example Refs. 7, 11). The BOTD machine consisted of a highly polished 12.7-mm-diameter ceramic ball $\left(\mathrm{Al}_{2} \mathrm{O}_{3}\right)$ pressed against three stationary steel disks under a load of $24.5 \mathrm{~N}$, creating a 
peak Hertz pressure of about $1 \mathrm{GPa}$. The steel disks were made of AISI 52100-grade steel and had a diameter of $6.35 \mathrm{~mm}$. Their surface finish was between 0.1 and $0.2 \mu \mathrm{m}$, RMS. The Rockwell C hardness value of the steel disks was 57 to 63. The lubricant cup of BOTD machine was filled with the diesel fuels, and the rubbing surfaces of the test materials were immersed in fuel throughout the tests. Rotational velocity of the ceramic ball was $60 \mathrm{rpm}$ and the test duration was $45 \mathrm{~min}$. At the conclusion of each test, the dimensions of the wear scars on the disk specimens were measured by an optical microscope equipped with a digital micrometer. The wear volumes and then wear rates of the tested flats were calculated with the formula of $\mathrm{W}_{\mathrm{b}}=\pi \mathrm{d}^{4} / 64 \mathrm{R}$ (where $\mathrm{d}$ is the wear scar diameter and $\mathrm{R}$ is the ball radius). The average wear rate in $\mathrm{mm}^{3} / \mathrm{N} . \mathrm{m}$ is the ball wear volume $\left(\mathrm{W}_{\mathrm{b}}\right)$ divided by the normal force (in newtons $(\mathrm{N})$ ) and the total sliding distance in meters (m). In terms of wear analyses, this is the most widely used procedure to assess the wear of sliding surfaces. Weight-lost measurement can also be used to assess wear, but it would have been almost impossible for the case of NFC coated balls in which the amount of wear was extremely small. Weight measurements in lubricated tests can also be complicated by possible surface reaction with sulfur and other additives that can lead to weight gain.

Fuel lubricity tests were performed with both the uncoated and coated disks. In our test program we primarily used diesel fuels that were prepared under a DOE-sponsored Diesel Emission Control- Sulfur Effects (DECSE) Program. These fuels contained sulfur ranging from 3 to 350 ppm. They also contained some aromatics and lubricity enhancing additives. For comparison, we also performed tests with a standard diesel fuel (containing $500 \mathrm{ppm} \mathrm{S}$ and $>28 \%$ aromatics) and a synthetic diesel fuel (Fischer-Tropsch) with no sulfur, aromatics, or lubricity additives. All tests were performed at room temperature and humidity of $35-40 \%$.

\section{RESULTS}

Figure 2 shows the location of Si bond-layer and the amorphous microstructure of the NFC films used in our study. As can be seen, the film is essentially featureless and tightly bonded to the substrate. Micro-laser Raman spectroscopy has confirmed that the NFC coating is a high-quality carbon film composed of both $\mathrm{sp}^{3}$-bonded diamond and $\mathrm{sp}^{2}$-bonded graphitic carbon. Figure 3 compares frictional performance of the NFC film with those of commercially available DLC coatings in a clean and dry nitrogen environment. As can be seen, the NFC film provides the lowest friction coefficient of all the films tested. These tests used a ball-on-disk type tribotest machine under a 10-N load (creating a peak Hertz pressure of $1 \mathrm{GPa}$ ) and at a sliding speed of 0.5 $\mathrm{m} / \mathrm{s}$. The balls used in these tests were made of 52100 steel and had a $9.5 \mathrm{~mm}$ diameter. Under the same test conditions, an uncoated steel ball against a steel disk would have given a friction coefficient of 0.9 .

Figure 4 summarizes the results of BOTD tests with uncoated as well as NFC-coated disks in DECSE fuels with varying amounts of sulfur. Results from a standard diesel fuel (with $500 \mathrm{ppm}$ $\mathrm{S}$ ) and a Fischer-Tropsch fuel (with zero $\mathrm{S}$ ) is also included. Table 2 gives the wear scar diameters and corresponding wear rates from all the tests samples evaluated in this study. The results in Fig. 4 and Table 2 reveal a close correlation between sulfur content of fuel and wear volume of steel samples. The largest scar was formed on flats tested in the Fischer-Tropsch fuel with zero sulfur as shown in Figure 5a. 
When the surfaces of test flats were coated with the new carbon film, the wear scar diameters were reduced drastically. Among the films tested, NFC-7 provided much better protection and lubricity than the other films. Figure 5b shows the size of wear scar formed on an NFC-7 coated test flat during a test in the Fischer-Tropsch fuel. Overall, the flats coated with super-low-friction carbon films suffered very little wear.

\section{DISCUSSION}

The results of BOTD tests demonstrate that with the use of super-slick NFC films, it is quite feasible to restore lubricity and to achieve very low wear in low-sulfur diesel fuels. Specifically, as shown in Figs. 4, when a thin NFC film is produced on the rubbing surfaces of steel disks, wear damage is drastically reduced. These test results proved that our films were very effective in reducing wear and improving the lubricity of rubbing surfaces in all the fuels tested. The one with NFC-7 designation provided the best overall performance in terms of reduced wear. This film provided excellent protection against wear even in Fischer-Tropsch fuel containing no sulfur. The wear scar formed on its surface (see Figure 5) was much smaller than that formed on an uncoated surface. We believe that highly inert, low-friction, and high wear resistant nature of our films were extremely important for achieving such low wear and high lubricity even in sulfur free diesel fuels.

Our test results further demonstrated that sulfur is an essential ingredient for diesel fuel lubricity. In DECSE fuels we used, the amount of aromatics and other additives were kept the same but the sulfur level was varied between $3 \mathrm{ppm}$ to $350 \mathrm{ppm}$. At $3 \mathrm{ppm}$ level, the amount of wear was much higher than that observed at $350 \mathrm{ppm}$. When sulfur is absent (in the case of Fischer-Tropsch), the wear damage on sliding steel surfaces is very high (see Fig. 4), thus further confirming the earlier findings that without some sulfur and/or aromatics, diesel fuels may lose their lubricity and thus cause severe wear damage. Retaining aromatics but removing sulfur from diesel fuels may provide some lubricity, however, higher aromatic content (especially di- and tri-aromatics) is known to result in higher amounts of particulate emissions [12-14]. As for the lubrication mechanism of sulfur in oils and fuels, researchers have confirmed that sulfur can react with rubbing surfaces and forms a protective boundary layer that can provide resistance to wear and scuffing [15-17]. If an artificial film with an extremely low friction coefficient (such as our NFC film) is applied on the sliding surfaces of steel samples, lubricity requirements of the test media are restored and wear damage is drastically reduced (regardless of the level of sulfur in the fuels) (see Fig. 5). It is possible that when a hard and slick film is present on the surface, the extent of chemical and/or mechanical interactions that control friction and wear are minimized. The lubricious DLC films used in our study is able to protect the softer steel substrate, and its low-friction nature provides the level of lubricity needed when low-sulfur diesel fuels are used. In short, we believe that the hard and very slick nature of DLC films play a key role in the extent of chemical and mechanical interactions that determine the friction and wear behavior of sliding surfaces in fuel environments.

\section{CONCLUSIONS}

The experimental results presented in this paper demonstrate that reducing sulfur in diesel fuels will result in severe wear of sliding metallic parts. Application of a hard and super-slick carbon film such as NFC can restore lubricity and also protect sliding surfaces against wear, regardless of the fuel type being used. 


\section{ACKNOWLEDGMENT}

This work was supported by the U.S. Department of Energy, Office of Transportation Technologies, under Contract W-31-109-Eng-38.

\section{REFERENCES}

1. M. Nikanjam and P. T. Henderson, “ Lubricity of Aromatic Diesel Fuels," SAE Tech. Paper No: 920825 (1992).

2. H. A. Spikes and D. P. Wei, 'Fuel lubricity - fundamentals and review', Proceedings of $1^{\text {st }}$ International Colloquium 'Fuels' (1997), Esslingen, Germany, 249-258.

3. P. I. Lacey and S. R. Westbrook, 'Diesel fuel lubricity', SAE Paper No. 950248.

4. J. C. Wang and D. J. Reynolds, "The Lubricity Requirement of Low Sulfur Diesel Fuels," SAE Paper No: 942015 (1994).

5. J. C. Wang and C. M. Cusano, "Predicting Lubricity of Low Sulfur Diesel Fuels," SAE Paper No: 952564 (1995).

6. M. Nikanjam, "Diesel Fuel Lubricity Additive Study," SAE Paper No: 942014 (1994).

7. M. Nikanjam, "Diesel Fuel Lubricity: On the Path to Specifications," SAE Paper No: 199901-1479.

8. C. Kajdas and M. Majzener, "Boundary Lubrication of Low-sulfur Diesel Fuel in the Presence of Fatty Acids," Proc. $2^{\text {nd }}$ Int. Colloquim on Fuels, W. J. Bartz, ed., Technische Akademie Esslingen, Ostfildern, Germany, pp. 219-238 (1999).

9. A. Erdemir, O. L. Eryilmaz, and G. Fenske, "Synthesis of Diamondlike Carbon Films With Superlow Friction And Wear Properties. J. Vac. Sci. Technol., A18(2000)1987.

10. A. Erdemir, O. L. Eryilmaz, I. B. Nilufer, and G. Fenske, "Synhesis of Superlow Friction Carbon Films from Highly Hydrogenated Methane Plasmas," Surf. Coat. Technol., 133134(2000)448.

11. C. D. Gray, G. D. Webster, R. M. Voitik, P. ST Pierre, and K. Michell, "Falex Ball-onThree Disk (BOTD-M2) Uset to Determine the Low Temperature Lubricity and Associated Characteristics of Lubricty Additives for Diesel Fuels," Proc. $2^{\text {nd }}$ Int. Colloquim on Fuels, W. J. Bartz, ed., Technische Akademie Esslingen, Ostfildern, Germany, pp. 211-217 (1999).

12. X. Li, W. L. Wallace, L. Chippior, and O. L. Gulder, "Effects of Fuel Properties on Exhaust Emissions of a Single Cylinder DI Diesel Engine," SAE Paper No. 962116.

13. D. Naber, W. W. Lange, A. A. Reglitzky, A. Schafer, M. Gairing and A. Le'Jeune, "The Influence of fuel properties on exhaust emissions from advance Mercedes Benz diesel engines," SAE Paper No. 932685.

14. K. Mitchell, D. E. Steere, J. A. Taylor, B. Manicom, J. E. Fisher, E. J. Sienicki, C. Chiu, and P. Williams, "Impact of Diesel Fuel Aromatics on Particulate, PAH and Nitro-PAH Emissions," SAE Paper No. 942053.

15. C. McFadden, C. Soto, and N. C. Spencer, Adsorption and surface chemistry in tribology, Tribol. Int. 30(1997)881.

16. D. Wei and H. A. Spikes, “The Lubricity of Diesel Fuels," Wear, 111, pp. 217-235 (1986).

17. S. D. Robertson, G. J. Hitchings, and J. Lin., "Lubricity for Modern Diesel Fuels," Proc. Slotrib 96, J. Vizintin, ed., University of Lujbljana, Solvenia, pp 87-102, 1(996). 


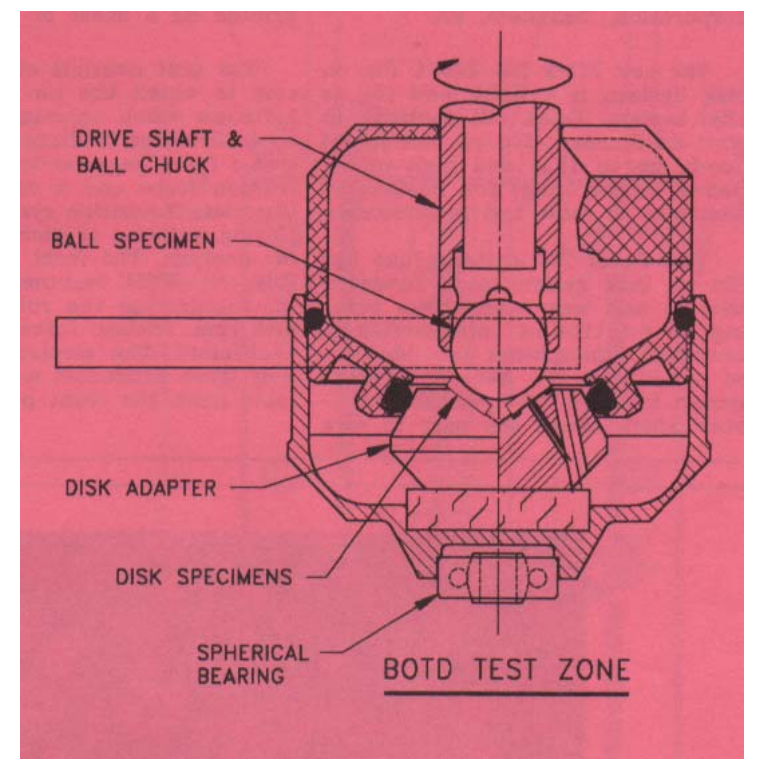

Figure 1. A schematic illustration of ball-on-three-disk (BOTD) fuel lubricity test machine.

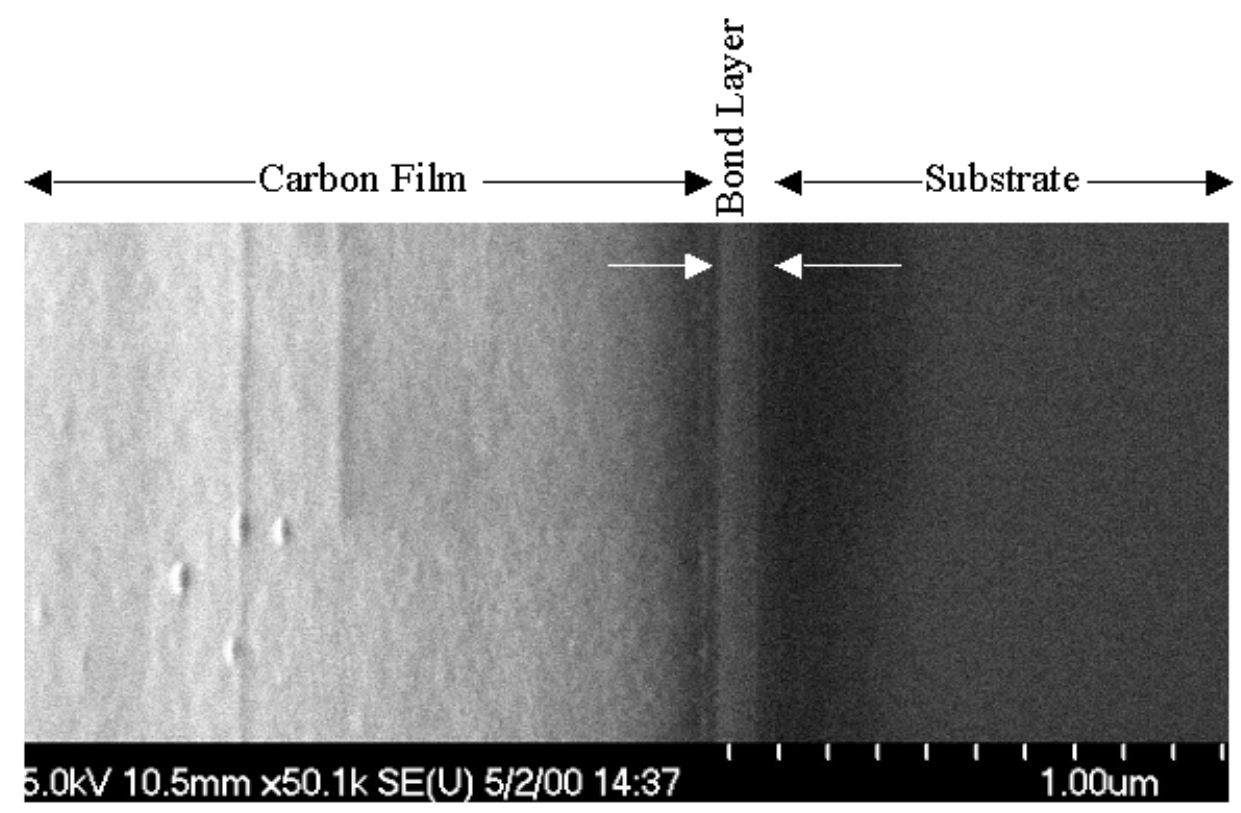

Figure 2. Cross-sectional scanning electron micrograph of an NFC film showing film and interface morphology. 


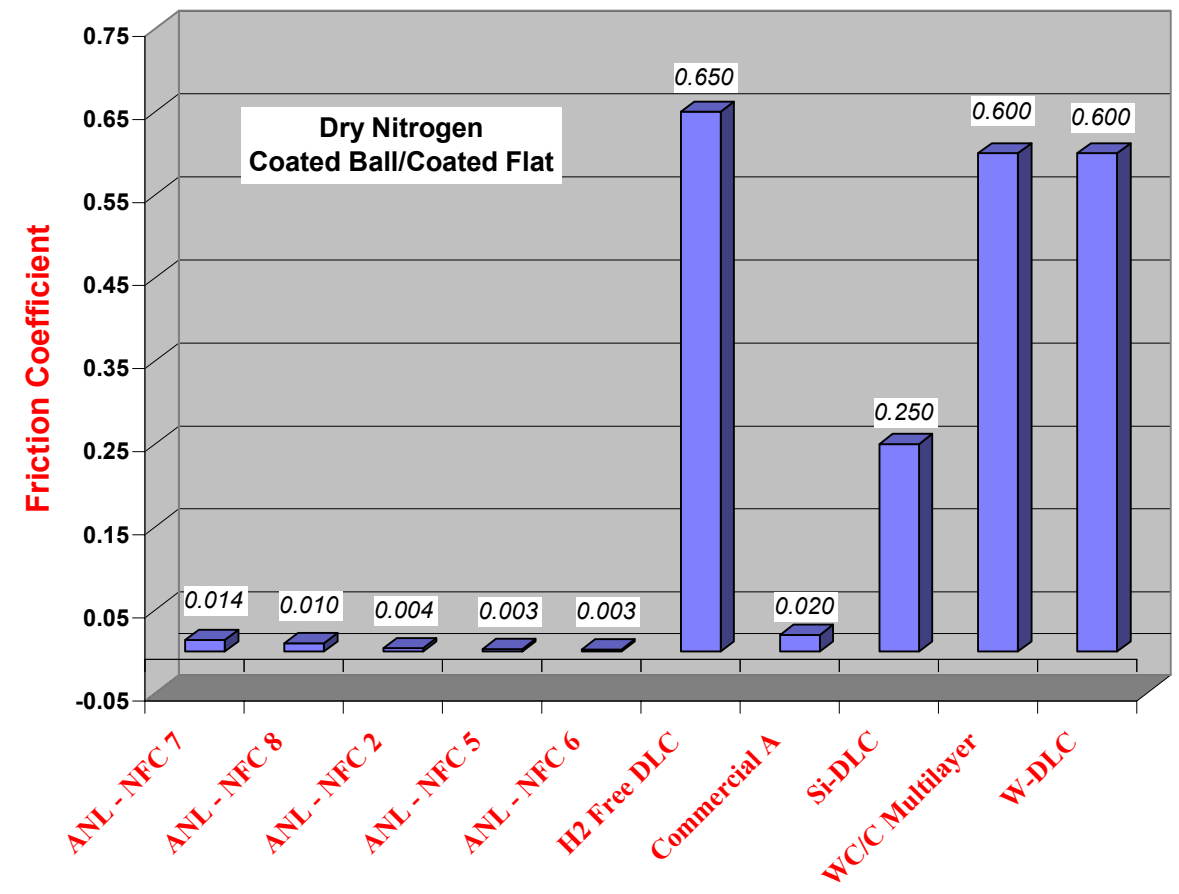

Figure 3. Comparison of frictional performance of near-frictionless carbon (NFC) films with that of commercial diamondlike carbon films.

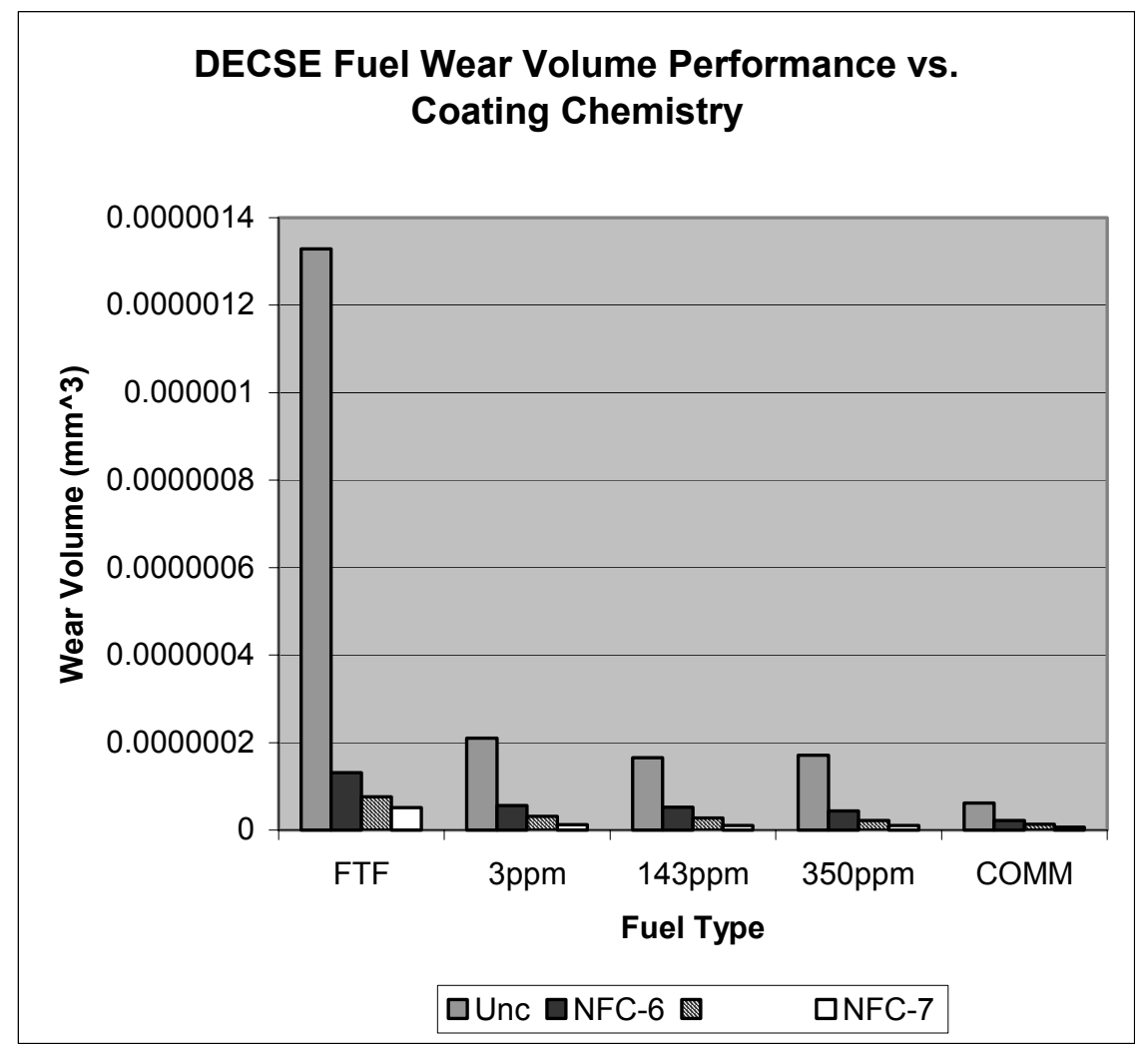

Figure 4. Wear performance of NFC films in various DECSE fuels. Test results from Fischer Tropsch (FTF) and commercial (COMM) diesel fuels are also included. 


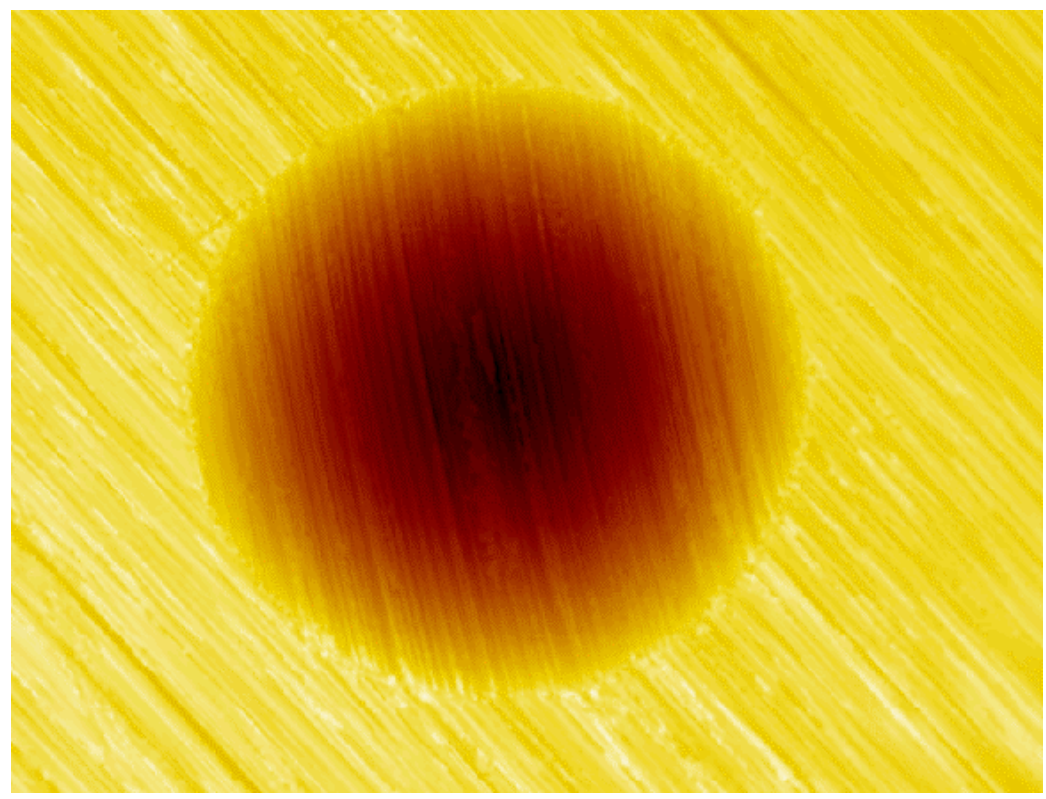

(a)

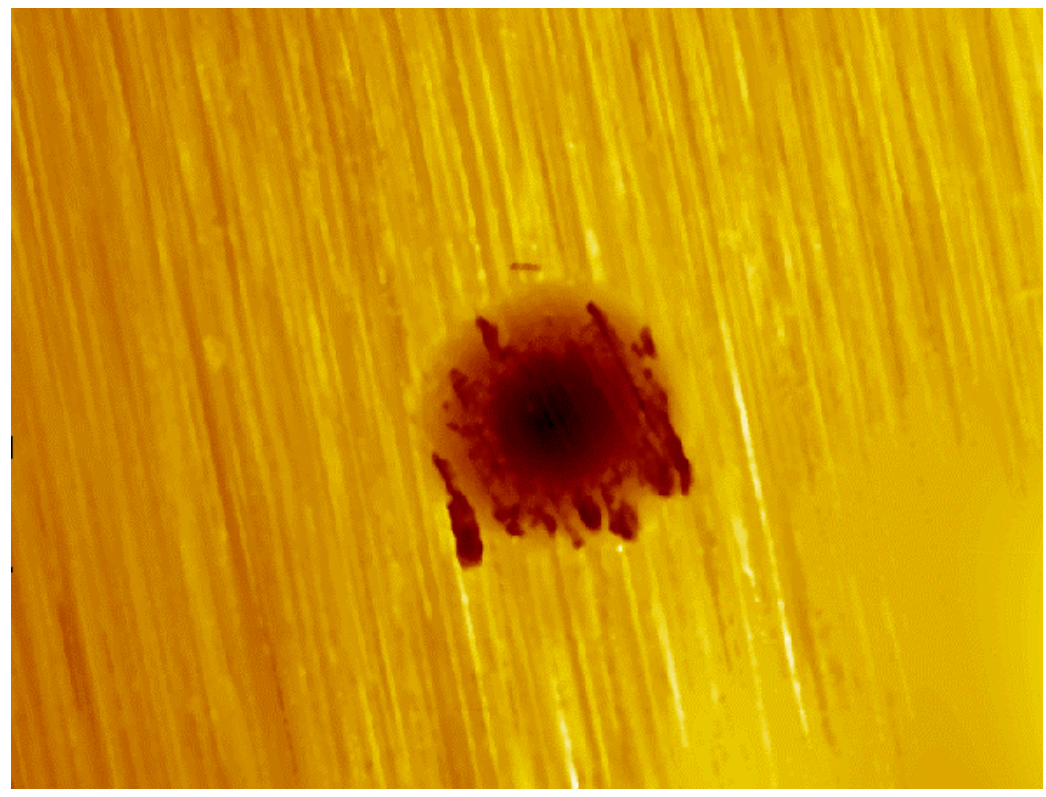

(b)

Figure 5. Size and morphology of typical wear scars formed on an (a) uncoated and (b) NFC coated disk during tests in Fischer Tropsch fuel. (Magnicifation: 6.3X) 